Journal of Bangladesh Academy of Sciences, Vol. 37, No. 2, 121-129, 2013

\title{
INVESTIGATION OF THE CORRELATION BETWEEN MICROSTRUCTURE AND HYSTERESIS CURVE OF $\mathrm{Li}_{0.5-\mathrm{x} / 2} \mathrm{Cu}_{\mathrm{X}} \mathrm{Fe}_{2.5-\mathrm{x} / 2} \mathrm{O}_{4}$ FERRITES
}

\author{
M. SAMIR ULLAH*, S. MANJURA HOQUE ${ }^{1}$ AND F. A. KHAN \\ Department of Physics, Bangladesh University of Engineering and Technology (BUET), \\ Dhaka-1000, Bangladesh
}

\begin{abstract}
$\mathrm{Cu}$ substituted lithium ferrites with composition $\mathrm{Li}_{0.5-\mathrm{x} / 2} \mathrm{Cu}_{\mathrm{x}} \mathrm{Fe}_{2.5-\mathrm{x} / 2} \mathrm{O}_{4}$ (where $\mathrm{x}=0.0,0.1,0.2$, 0.4 and 0.6 ) were synthesized by conventional double sintering ceramic technique and sintered at $1100^{\circ} \mathrm{C}$ for 3 hours in the normal atmosphere. The microstructures for the samples of different compositions were examined by scanning electron microscope (SEM). The average grain size was determined by the linear intercept method which demonstrates that the average grain size increases with the increase of $\mathrm{Cu}$ content. The initial permeability was found to increase with $\mathrm{Cu}$ content, $\mathrm{x}$, which is attributed to increase of grain size of the samples. The parameters of hysteresis curve have been determined at room temperature by B-H Loop Tracer. It was found that coercivity and initial permeability were closely related to each other which are mainly governed by the anisotropy and grain size of the mixed ferrites.
\end{abstract}

Key words: Average grain size, Coercivity, Initial permeability

\section{INTRODUCTION}

Ferrimagnetic substances, often referred to as ferrites, are certain double oxides of iron and another metal whose chemical composition is of the form $\mathrm{MO} \cdot \mathrm{Fe}_{2} \mathrm{O}_{3}$ or $\mathrm{MFe}_{2} \mathrm{O}_{4}$, where $\mathrm{M}$ signifies a divalent metal. These generally crystallize in the spinel structure (Omar 2000). Spinel ferrites exhibit certain important electrical and magnetic properties, which make them useful in technological and industrial applications (Viswanathan et al. 1990). Nowadays, soft ferrites are very important for researchers due to their various potential applications such as microwave and satellite communication, radars, transformer and magnetic recording (Randhawa et al. 2004, Pandya et al. 2005). The magnetic properties of ferrites depend on the chemical composition, heat treatment and type of additive or substituted ions (Sattar et al. 2007, Rezlescu et al. 1995). Squareness of the hysteresis loop along with superior high temperature performance due to their high curie temperature has made them very promising candidates for microwave devices (Maisnam et al. 2008, Bellad et al. 2000). Several workers investigated the properties of lithium ferrite with the substitution of various ions (Mazen et al. 1993,

*Corresponding author: <samirullah@phy.buet.ac.bd>.

${ }^{1}$ Materials Science Division, Atomic Energy Center (AECD), Dhaka-1000, Bangladesh. 
Yousif et al. 1994, Ravinder et al. 2003). Few investigators have focused their attention on $\mathrm{Cu}$ substituted mixed spinel ferrite because $\mathrm{Cu}$ containing ferrites have interesting magnetic and electrical properties. In this study, an attempt was made to understand its microstructure-property relationship such as grain size, initial permeability and coercivity.

\section{MATERIALS AND METHOD}

$\mathrm{Li}_{0.5-\mathrm{x} / 2} \mathrm{Cu}_{\mathrm{x}} \mathrm{Fe}_{2.5-\mathrm{x} / 2} \mathrm{O}_{4}$ (where $\mathrm{x}=0.0,0.1,0.2,0.4$ and 0.6 , samples were prepared by conventional double sintering ceramic technique. $\mathrm{Li}_{2} \mathrm{CO}_{3}, \mathrm{CuO}$ and $\mathrm{Fe}_{2} \mathrm{O}_{3}$ of high purity were mixed homogeneously having appropriate ratio of cations. The resultant powder was then ball milled for 5 hours to produce fine powders of mixed constituents. The samples were dried and the dried powder was pressed into disc shape. The disc-shaped samples were pre-fired at $1000^{\circ} \mathrm{C}$ for 3 hours in air to form ferrite through solid state reaction. The raw ferrite was wet milled extensively to get fine powder. The powder was then dried and mixed with polyvinyl alcohol as a binder for granulation. Then the granulated powder was pressed into desired shapes using metal dies. Dies of several shapes were used for pressing. Finally pressed products were sintered at $1100^{\circ} \mathrm{C}$ in air for 3 hours. Formation of ferrite was confirmed by Philips analytical X-ray diffractometer using $\mathrm{CuK}_{\alpha}$ radiation. Crystal structure was determined from XRD data. Microstructural features for the samples of different composites were examined using scanning electron microscope (SEM). The grain size was determined by the linear intercept method. B-H loops were measured by using B-H Loop Tracer. Initial permeability of the toroid shaped samples was measured with the help of impedance analyzer.

\section{RESULTS AND DISCUSSION}

For the specimen of polycrystalline $\mathrm{Li}-\mathrm{Cu}$ ferrite, structure was investigated using X-ray diffraction. The powder x-ray diffraction patterns exhibited that all the samples were identified as a spinel structure. The experimental lattice parameter $\left(a_{\text {exp }}\right)$ was determined through the Nelson-Riley extrapolation method (Culity 1959) and presented in Table 1. An increase in lattice parameter with increase in the $\mathrm{Cu}$ content can be attributed to the ionic size differences since the unit cell has to expand when substituted by ions with larger ionic size. It does not follow the Vegard's law (Denton et al. 1991) because of the structural change at higher $\mathrm{Cu}$ content. The theoretical lattice parameter $\left(a_{t h}\right)$ was calculated from the cation distribution of tetrahedral (A-site) and octahedral (Bsite) (Mazen et al. 1999). The discrepancy between $\mathrm{a}_{\exp }$ and $\mathrm{a}_{\text {th }}$ can be explained by the qualitative IR analysis (Mazen 2000) indicated that the concentration of $\mathrm{Fe}^{2+}$ ions in the samples with low values of $\mathrm{x}$ is larger than that with high values of $\mathrm{x}$. The increase of $\mathrm{Cu}^{2+}$ ion content tends to decrease the creation of $\mathrm{Fe}^{2+}$. 
The micro-structural study was performed in order to observe the size and shape of the grains. Fig. 1 shows the SEM micrograph of the samples sintered at $1100^{\circ} \mathrm{C}$ of different compositions. The SEM micrograph was taken on polished surfaces of the samples. The upper surfaces of the grains seem to be just like the etched surface in the samples with $\mathrm{x}=0.0,0.1,0.2,0.4$ and 0.6 . The driving force for grain growth is the surface tension of the grain boundary. It is necessary that most of the grain boundaries be curved, because grains have various numbers of sides. When many pores are present and the sintering temperature is not too high for certain compositions, grain growth is inhibited. As a result, many pores become isolated from grain boundaries and diffusion distance between pores and grain boundaries become large. During the sintering process, a force is generated due to thermal energy, which drives the grain-boundaries to grow over pores, thereby decreasing the pores volume and making the materials dense. The smaller value of grain size for $x=0.0$ could be due to more porosity. The porosity of ceramic samples come from two sources, intergranular porosity and intragranular porosity (Hoque et al. 2002, Kingery et al. 1975). The intergranular porosity mainly depends on the grain size. The average grain size was calculated by the linear intercept method. It was observed that average grain diameter increased with increasing of $\mathrm{Cu}$ content and presented in Fig. 2. This may be ascribed to the activated sintering and increasing driving force during sintering (William 2001).

Table 1. Experimental lattice parameter $\left(a_{\exp }\right)$ and theoretical lattice parameter $\left(a_{t h}\right)$ of $\mathrm{Li}_{0.5-\mathrm{x} / 2} \mathrm{Cu}_{\mathrm{x}} \mathrm{Fe}_{2.5-\mathrm{x} / 2} \mathrm{O}_{4}$.

\begin{tabular}{ccc}
\hline Cu content, $\mathbf{x}$ & $\mathbf{a}_{\exp }\left(\mathbf{\prime}^{\prime}\right)$ & $\mathbf{a}_{\text {th }}\left(\mathbf{\prime}^{\prime}\right)$ \\
\hline 0.0 & 8.341 & 8.254 \\
0.1 & 8.381 & 8.271 \\
0.2 & 8.388 & 8.282 \\
0.4 & 8.399 & 8.299 \\
0.6 & 8.375 & 8.315 \\
\hline
\end{tabular}

In Fig. 3, the real part of the complex initial permeability $\mu_{\mathrm{i}}$ up to $f=13 \mathrm{MHz}$ have been presented for different composition in the range $0 \leq x \leq 0.6$, sintered at $1100^{\circ} \mathrm{C}$. The general characteristic of the curves in Fig. 3 is that $\mu^{\prime}$ remains fairly constant in the frequency range shown in the figure up to some critical frequency characterized by the onset of resonance. This phenomenon is called ferrimagnetic resonance. This trend of the curve is clearly visible for higher $\mathrm{Cu}$ content. The resonance frequency peaks are the result of the absorption of energy due to the matching of the oscillation frequency of the magnetic dipoles and the applied frequency.

Permeability is defined as the proportionality constant between the magnetic induction, B and the applied field intensity, H (Valenzuela 1994). If the applied field is 
very low and approaching to zero, this ratio will be called as the initial permeability (Chikazumi 1966). The compositional variation of initial permeability with $\mathrm{Cu}$ content is shown in Fig. 4.

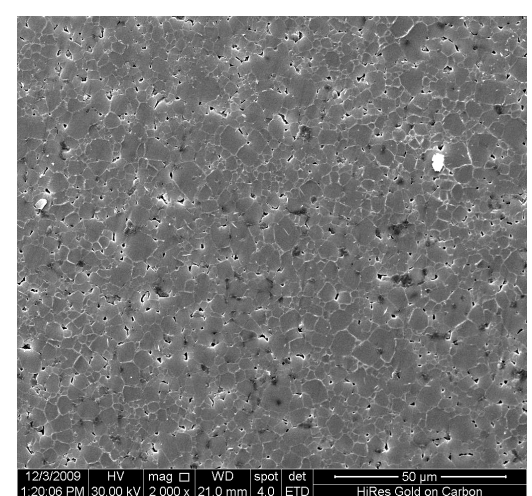

$\mathrm{x}=0.0$

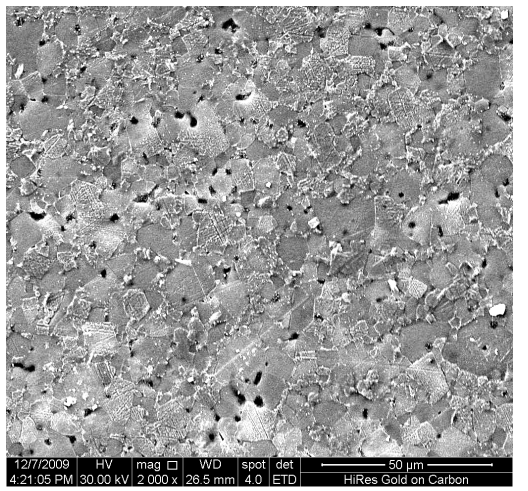

$\mathrm{x}=0.2$

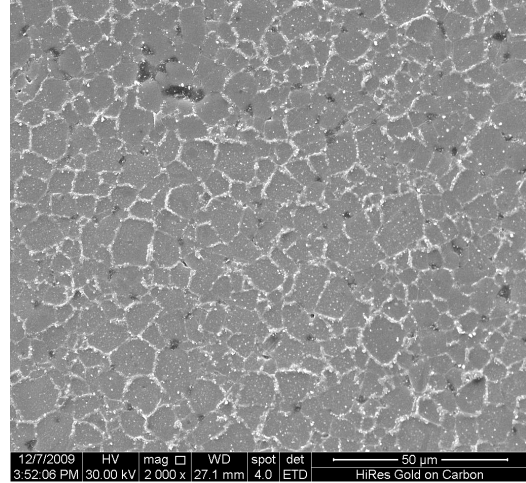

$\mathrm{x}=0.1$

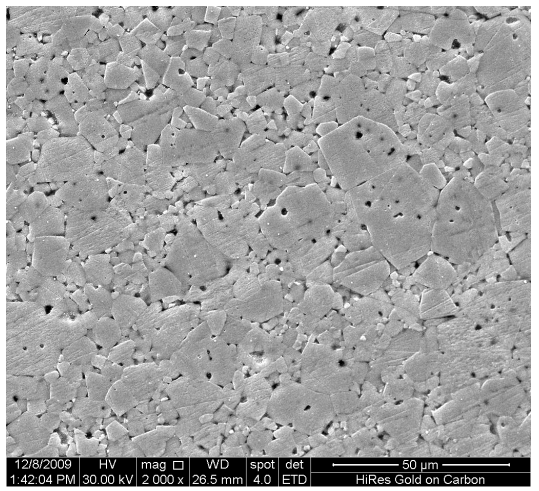

$\mathrm{x}=0.4$

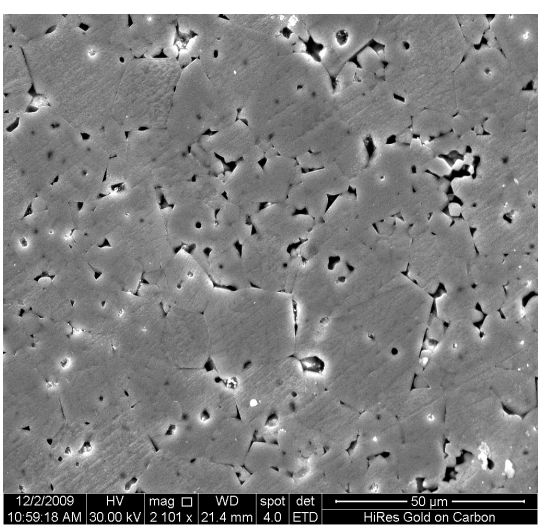

$\mathrm{x}=0.6$

Fig. 1.The microstructures of $\mathrm{Li}_{0.5-\mathrm{x} / 2} \mathrm{Cu}_{\mathrm{x}} \mathrm{Fe}_{2.5-\mathrm{x} / 2} \mathrm{O}_{4}$ samples sintered at $1100^{\circ} \mathrm{C}$. 
The permeability can be expressed as $\mu=1+\chi_{\text {spin }}+\chi_{\mathrm{dw}}$, where $\chi_{\text {spin }}$ is the magnetic susceptibility due to spin and $\chi_{\mathrm{dw}}$ is the susceptibility due to domain wall motion. $\chi_{\text {spin }}$ and $\chi_{\mathrm{dw}}$ are written as $\chi_{\mathrm{dw}}=3 \pi \mathrm{M}_{\mathrm{s}}{ }^{2} \mathrm{D} / 4 \gamma$ and $\chi_{\text {spin }}=2 \pi \mathrm{M}_{\mathrm{s}}{ }^{2} / \mathrm{K}$, where $\mathrm{M}_{\mathrm{s}}, \mathrm{K}, \mathrm{D}$ and $\gamma$ are the saturation magnetization, anisotropic energy, average grain diameter and domain wall energy, respectively (Slick 1980). For polycrystalline ferrites, pores and other imperfections are unavoidable, which generate a demagnetizing field $\left(\mathrm{H}_{\mathrm{d}}\right)$. An increase in the density of the $\mathrm{Cu}$ contents not only results in the reduction of demagnetizing field due to reduction of pores but also rises the spin rotational contribution, which in turn increases permeability. The larger grains favour the domain wall mobility giving rise to high permeability.

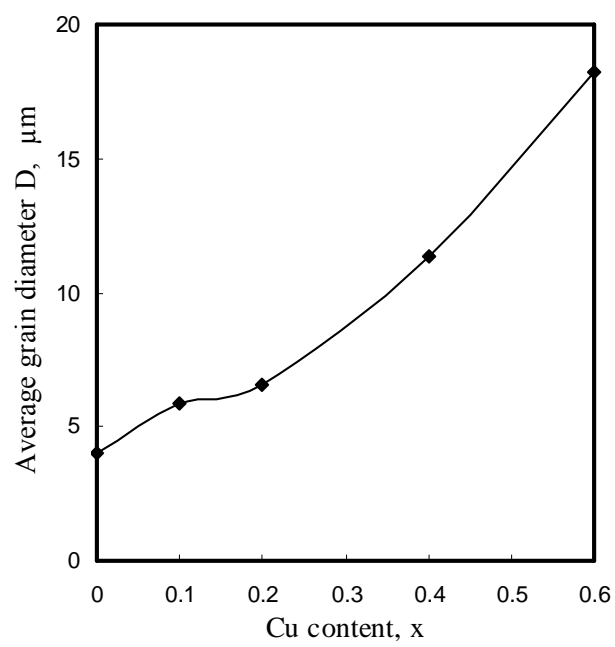

Fig. 2. Variation of average grain diameter with $\mathrm{Cu}$ content forLi $\mathrm{i}_{0.5-\mathrm{x} / 2} \mathrm{Cu}_{\mathrm{x}} \mathrm{Fe}_{2.5-\mathrm{x} / 2} \mathrm{O}_{4}$.

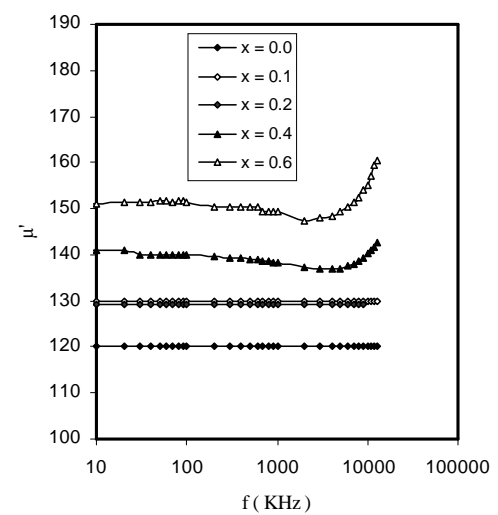

Fig. 3. Variation in the real part of initial permeability $\left(\mu^{\prime}\right)$ forLi $\mathrm{i}_{0.5-\mathrm{x} / 2} \mathrm{Cu}_{\mathrm{x}} \mathrm{Fe}_{2.5-\mathrm{x} / 2} \mathrm{O}_{4}$.

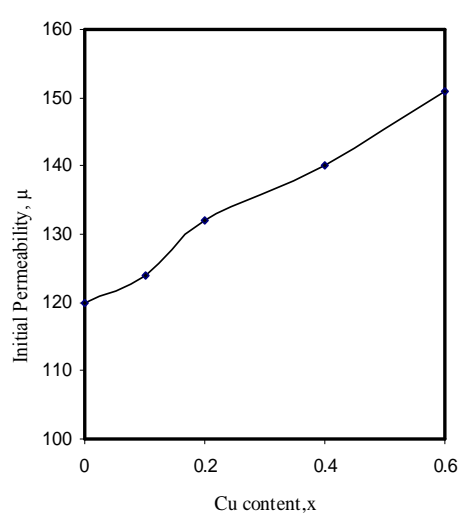

Fig. 4. Variation of initial permeability with $\mathrm{Cu}$ content for $\mathrm{Li}_{0.5-\mathrm{x} / 2} \mathrm{Cu}_{\mathrm{x}} \mathrm{Fe}_{2.5-\mathrm{x} / 2} \mathrm{O}_{4}$. 
The B-H loops of the $\mathrm{Li}_{0.5-\mathrm{x} / 2} \mathrm{Cu}_{\mathrm{x}} \mathrm{Fe}_{2.5-\mathrm{x} / 2} \mathrm{O}_{4}$ ferrite samples were measured at room temperature for the sintering temperature of $1100^{\circ} \mathrm{C}$ at constant frequency $\mathrm{f}=1200 \mathrm{~Hz}$ and is shown in Fig. 5. The properties of hysteresis curve such as the coercivity and hysteresis loss are very useful information from the technological point of view.
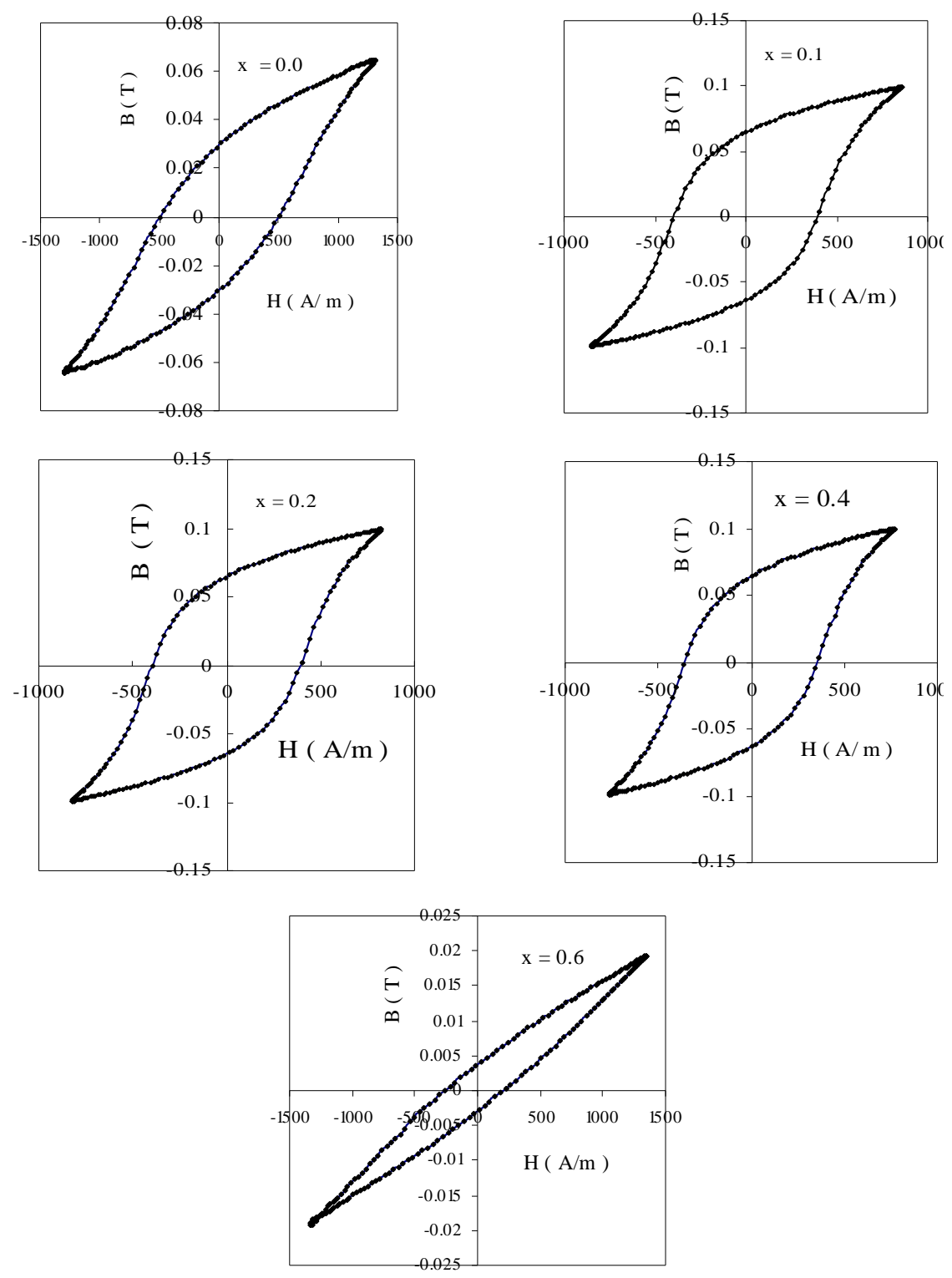

Fig. 5. B-H Loops of $\mathrm{Li}_{0.5-\mathrm{x} / 2} \mathrm{Cu}_{\mathrm{x}} \mathrm{Fe}_{2.5-\mathrm{x} / 2} \mathrm{O}_{4}$ ferrites samples sintered at $1100^{\circ} \mathrm{C}$. 
The coercivity of $\mathrm{Li}_{0.5-\mathrm{x} / 2} \mathrm{Cu}_{\mathrm{x}} \mathrm{Fe}_{2.5-\mathrm{x} / 2} \mathrm{O}_{4}$ ferrites is presented in Fig. 6. It was found that coercivity decrease with the increase of $\mathrm{Cu}$ content and this variation has inverse trend with the variation of initial permeability with $\mathrm{Cu}$ content as shown in Fig. 4 . It is known that coercivity is an extrinsic property, which depends on the grain size, inter and intragranular porosity (Hoque et al. 2011). As the porosity increases higher field is needed to push the domain wall, which in turn increases coercivity. This is due to the fact that the easy motion of domain wall with increasing grain size turn to low coercivity at higher $\mathrm{Cu}$ content. Further, since $\mathrm{CuFe}_{2} \mathrm{O}_{4}$ has lower magnetic anisotropy than $\mathrm{Li}_{0.5} \mathrm{Fe}_{2.5} \mathrm{O}_{4}$ (Smith et al. 1959), this leads to increase the magnetic softness due to decrease of coercivity with increasing of $\mathrm{Cu}$ content. The area within the hysteresis loops is related to the hysteresis loss. The lower value of induction and coercivity reduce the area within the loop for the composition of $\mathrm{x}=0.6$.

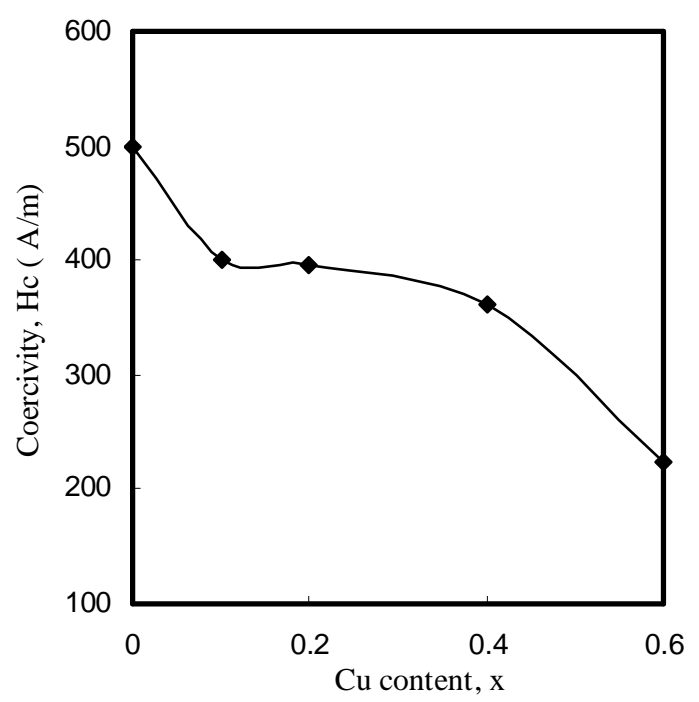

Fig. 6. Variation of coercivity $\left(\mathrm{H}_{\mathrm{c}}\right)$ with $\mathrm{Cu}$ content for $\mathrm{Li}_{0.5-\mathrm{x} / 2} \mathrm{Cu}_{\mathrm{x}} \mathrm{Fe}_{2.5-\mathrm{x} / 2} \mathrm{O}_{4}$.

\section{CONCLUSIONS}

Interesting correlation of microstructure and hysteresis curve has been established for $\mathrm{Cu}$ substituted $\mathrm{Li}$-ferrite in the range of compositions studied. The initial permeability increases with $\mathrm{Cu}$ content, $\mathrm{x}$ and is governed by large grain size and small anisotropy constant. With the addition of $\mathrm{Cu}$ content, coercivity decreases due to the increase of magnetic softness. All compositions exhibit low coercivity and high permeability values, which is typical for soft ferrites. 


\section{ACKNOWLEDGMENTS}

The authors gratefully acknowledge the authorities of the Department of Physics, Bangladesh University of Engineering and Technology (BUET), Dhaka and Materials Science Division, Atomic Energy Center Dhaka, (AECD) for providing support to carry out this work.

\section{REFERENCES}

Bellad, S. S., C. S. Watawe, M. A. Shaikh and K. B. Chougule. 2000. Cd substituted high permeability Li ferrite Ind. Acd. Sci. Bull. Mater. Sci. 23(2), pp. 83-85.

Chikazumi, S. 1966. Physics of Magnetism, Jhon Wiley \& Sons, Inc., New York.

Culity, D. B. 1959. Elements of X-ray Diffraction, Addison-Wesley Publishing Company, Inc., Massachusetts, Second Printing.

Denton, R. A. and W. N. Ashcroft. 1991. Vegard's law. Phys. Rev. A 43. pp. 3161.

Hoque Manjura, S., A. M., Choudhury and F. M. Islam. 2002. Characterization of Ni-Cu Mixed Spinel Ferrite. J. Magn. Magn. Mater. 251 : 292-303.

Hoque Manjura, S., M. Ullah Samir, A. F. Khan, A. M. Hakim and K. D. Saha. 2011. Structural and magnetic properties of Li-Cu mixed spinel ferrites. Physica B 406: 1799-1804.

Kingery, D. W. K. H. Bowen, and R. D. Uhlmann. 1975. Introduction to ceramic Science. Wiley, New York. pp. 474.

Maisnam, M., S. Phanjoubam, K. N. H. Sarma, P. O. Thakur, L. Devi Radhapiyari and Prakash Chandra. 2008, Influence of temperature on the dielectric behaviour of $\mathrm{Co}^{2+}$ substituted Li-NiMn ferrites. Ind. J. Engg. Mat. Sci. 15 : 199.

Mazen, A. S., H. M. Abdullah, I. R. Nakhla, F. Metawe and M. H. Zaki. 1993. X-ray analysis and IR absorption spectra of Li-Ge ferrite. Mater. Chem. Phys. 34 : 35-40.

Mazen, A. S. and A. H. Dawoud. 1999. Structure and Magnetic properties of Li-Cu Ferrite. Phys. Status Solidi (a) 172: 275-289.

Mazen, A. S. 2000. Infrared absorption and dielectric properties of $\mathrm{Li}-\mathrm{Cu}$ ferrite. Mater, Chem. Phys. 62: 139-147.

Omar Ali, M. 2000. Elementary Solid State Physics. Addison-Wesley. pp. 453.

Pandya, P. M., B. K. Modi and H. H. Joshi. 2005. Study of conduction mechanism in aluminium and magnesium co-substituted lithium ferrite. J. Mat. Sci. 40: 5223-5232.

Randhawa, S. B., J. K. Sweety, Kaur Manpreet and M. J. Greneche. 2004. Synthesis of ferrites: Thermal analysis of some transition metal tris (maleato) ferrates (III). J. Them. Anal. Calo. 75: $101-111$.

Ravinder, D. and B. V. P. Reddy, 2003, Thermoelectric power studies of polycrystalline magnesium substituted lithium ferrites. J. Magn. Magn. Mater. 263: 127-133.

Rezlescu, N. and E. Rezlescu. 1995. The influence of additives on the material parameters of Li-Zn ferrites. Phys. Stat. Sol. (a) 147: 553-562.

Sattar, A. A., M. H. El-Sayed, R. W. Agami and A. A. Ghani. 2007. Magnetic Properties and Electrical Resistivity of $\mathrm{Zr}^{4+}$ Substituted Li-Zn Ferrite. J. Appl. Sci. 4(2): 89-93. 
Slick, P. I. 1980. Ferromagnetic Materials. Vol. 2, In: E.P. Wohlforth (Ed.), North-Holland, Amsterdam.

Smith, J. and H. P.J. Wijn. 1959. Ferrites. Wiley-Interscience, New York.

Valenzuela, R. 1994. Magnetic Ceramics. Cambridge University Press, Cambridge.

Viswanathan, B. and K. R. V. Murthy. 1990. Ferrite Materials. Springer-Verlag, Berlin.

William, D. Callister. 2001. An Introduction Materials Science and Engineering, John Wiley \& Sons, Inc.

Yousif, A. A., E. Elazain, A. S. Mazen, H. H. Sutherland, H. M. Abdullah and S. F. Mansour. 1994. A Mossbauer and X-ray diffraction investigation of Li-Ti ferrites. J. Phys. Condensed Matter 6 : 5717-5721.

(Received revised manuscript on 8 July, 2013) 